DOI: https://doi.org/10.47405/mjssh.v6i11.1157

\begin{tabular}{|c|c|}
\hline & Malaysian Journal of Social Sciences and Humanities (MJSSH) \\
\hline Malaysian Journal of & Volume 6, Issue 11, November 2021 \\
\hline (MJ-SSH) & e-ISSN : 2504-8562 \\
\hline & $\begin{array}{l}\text { Journal home page: } \\
\text { www.msocialsciences.com }\end{array}$ \\
\hline
\end{tabular}

\title{
Sikap Pengguna Milenial Melalui Perspektif Budaya Terhadap Pengiklanan Media Sosial
}

\author{
Hamimda Agil1 ${ }^{1}$ Abdul Latiff Ahmad², Arina Anis Azlan² \\ ${ }^{1}$ Fakulti Komunikasi dan Pengajian Media, Universiti Teknologi MARA, Shah Alam, Selangor, Malaysia \\ 2Pusat Penyelidikan Media dan Komunikasi, Fakulti Sains Sosial dan Kemanusiaan, \\ Universiti Kebangsaan Malaysia (UKM), Malaysia \\ Correspondence: Hamimda binti Agil (hamimda@uitm.edu.my)
}

\begin{abstract}
Abstrak
Pengiklan pada hari ini banyak bergantung kepada platform pengiklanan dalam talian terutama sekali media sosial untuk mempromosikan jenama pemasar kerana platform ini dilihat lebih berkesan, membuka ruang untuk pengiklan berkreativiti selain dari ianya merupakan satu pelaburan yang menguntungkan kerana kos pembelian media yang jauh lebih murah daripada platform media pengiklanan yang lain. Justeru, adalah amat penting bagi pengiklan untuk memahami sikap pengguna terutama sekali pengguna Milenial terhadap pengiklanan di media sosial memandangkan mereka merupakan generasi yang paling aktif menggunakan media sosial. Sikap pengguna terhadap iklan mempengaruhi tindak balas mereka terhadap pengiklanan, dan tingkah laku tindak balas pengguna seperti mengelak daripada melihat iklan dalam talian adalah berpunca daripada sikap negatif mereka terhadap pengiklanan yang mungkin disebabkan oleh pengaruh budaya yang terbukti dapat mempengaruhi tingkah laku dan penggunaan pengguna. Budaya yang berbeza kebiasaannya mewujudkan perbezaan dari segi kepercayaan, sikap, dan nilai dan nilai yang berbeza mungkin membawa kepada perbezaan keperluan dan tingkah laku penggunaan. Model Dimensi Budaya Hofstede dan Teori Budaya Hall merupakan model dan teori yang paling banyak digunakan untuk mengenal pasti dan menganalisis budaya mengikut tahap konteks dalam sistem komunikasi manusia.
\end{abstract}

Kata kunci: pengiklanan media sosial, budaya, sikap pengguna, pengguna milenial

\section{The Cultural Perspective of Milennial Consumer Attitude Toward Social Media Advertising}

\begin{abstract}
Today's advertisers prefer to promote brands through social media platforms because it is more effective, allows creativity, and a low cost investment as this media space is inexpensive than other platforms. Thus it is important for advertisers to understand the attitude of consumers especially the Millennials toward social media advertising as they are actively using social media on a daily basis. Consumer attitudes toward advertising will influence their response to advertising and the behaviour of avoiding online ads are due to their negative attitudes toward advertising that may be due to cultural influences that has been recognised to affect consumer behaviour and consumption. Different cultures naturally create differences in terms of beliefs, attitudes and vales and different values may lead to differences in consumption and behaviours. Hofstede's Cultural Dimension Model and Hall's Cultural
\end{abstract}


Theory are the most widely used models to identify and analyse culture according to the level of context in human communication systems.

Keywords: social media advertising, culture, consumer's attitude, Millennials' consumer

\section{Pengenalan}

Media sosial mendapat sambutan yang meluas oleh pengguna sejak pengenalannya dan ini menyebabkan ramai pengiklan mula meneliti kembali strategi komunikasi mereka. Sejak itu, semakin ramai pengiklan mula memberi tumpuan dalam penghasilan pengiklanan di media sosial. Hari ini media sosial bukan hanya alat untuk meluangkan masa, tetapi merupakan alat pemasaran yang utama untuk berkomunikasi secara langsung dengan pengguna sedia ada dan pengguna yang berpotensi. Ia membantu meningkatkan nilai jenama melalui penglibatan dengan pengguna yang meluas (Saha, Kumar, Jannat, \& Nahar, 2021). Atribut pengiklanan media sosial yang paling menonjol adalah potensi dialogisnya dan kemampuannya untuk mengesan tindak balas tingkah laku pengguna (Al Kurdi \& Alshurideh, 2021). Pengiklanan media sosial mempunyai keupayaan membina sesuatu jenama yang kuat (Ibrahim, 2021). Kajian ke atas pengiklanan media sosial dan pengiklanan dalam talian secara umumnya telah menunjukkan bahawa sikap pengguna terhadap pengiklanan media sosial adalah penentu utama kepada keberkesanannya (Rajakrishnan \& Brindha, 2021; Li et al., 2002; Chu et al., 2013). Sekali lagi, beberapa kajian menunjukkan kaitan antara sikap pengguna terhadap pengiklanan dan tindak balas tingkah laku mereka. Pengguna yang mempunyai sikap positif terhadap iklan menunjukkan sambutan yang baik, manakala mereka yang mempunyai sikap negatif terhadap iklan menunjukkan tingkah laku yang negatif (van Berlo, van Reijmersdal \& Eisend, 2021). Dalam kes ini, boleh dikatakan bahawa pengguna yang mempunyai sikap positif terhadap pengiklanan di media sosial akan menunjukkan sambutan yang baik dan sebaliknya (van Ooijen \& Segijn, 2020). Walau bagaimanapun, menurut Mehta (2000), sikap pengguna terhadap pengiklanan adalah salah satu petunjuk yang paling berpengaruh sejak kemampuan kognitif pengguna terhadap pengiklanan terpancar dalam pemikiran dan perasaan mereka yang seterusnya mempengaruhi sikap mereka (Niu, Wang \& Liu, 2020). Pemasar perlu memahami tingkah laku pembelian pengguna apabila merancang iklan yang diingini. Iklan memainkan peranan penting dalam membentuk imej sesuatu produk dalam minda pengguna. Fishbein (1967) mendefinisikan sikap sebagai "kecenderungan mempelajari manusia". Walau demikian, Bamoriya dan Singh (2011) mendefinisikan sikap terhadap pengiklanan sebagai tindak balas kepada iklan, sama ada dengan cara yang baik atau tidak. (Northey, Dolan, Etheridge, Septianto, \& van Esch, 2020). Fishbein dan Ajzen (1975) menekankan bahawa sikap adalah salah satu faktor paling menonjol yang mempengaruhi keputusan pembelian dan menentukan niat dan tingkah laku pengguna.

Tujuan kertas konsep ini adalah untuk membincangkan sikap pengguna milenial di Malaysia terhadap pengiklanan digital di media sosial. Pengiklanan terutama sekali pengiklanan digital merupakan elemen penting dan utama dalam aktiviti pemasaran. Magna, daripada kumpulan IPG Mediabrand menyasarkan peningkatan pendapatan media pengiklanan sebanyak 14 peratus pada tahun 2021, kini dijangka mencapai rekod sebanyak 657 bilion dolar Amerika yang mana menurut Magna merupakan peningkatan pendapatan pengiklanan terbesar dalam tempoh 40 tahun (MAGNA, 2021). Jika dilihat dalam konteks tempatan, dari segi aktiviti pengiklanan di Malaysia, gangguan yang berlaku pada tahun 2020 disebabkan oleh pandemik COVID19 telah menyebabkan penguncupan sebanyak -20 peratus tetapi Magna meramalkan bahawa 2021 akan menyaksikan peningkatan sebanyak 15.4 peratus. Manakala dari segi perbelanjaan pengiklanan digital di Malaysia, Magna meramalkan peningkatan sebanyak +19.3 peratus untuk mencapai RM2.9 bilion, mewakili 56 peratus daripada jumlah peruntukan yang merupakan peningkatan yang tinggi daripada peruntukan 40 peratus pada tahun 2019 (MAGNA, 2020).

\section{Pengguna Milenial}

Golongan milenial merupakan kumpulan generasi terbesar di Malaysia dengan generasi Y sebanyak 26 peratus dan generasi Z sebanyak 25 peratus (Worldometers, 2020). Ciri demografi memainkan peranan 
penting dalam tingkah laku pengguna dan boleh menyebabkan penyimpangan daripada model umum proses membuat keputusan pengguna (Topalova, 2021). Pengiklan telah lama mengkaji tentang kumpulan generasi untuk mengenal pasti persamaan dan perbezaan ciri utama mereka dalam usaha menggunakannya sebagai faktor penentu pemasaran dan penyesuaian strategi untuk mendapatkan khalayak yang sepatutnya.

Kebanyakan kajian sedia ada menurut Kraus (2018) membuktikan bahawa perbezaan generasi memainkan peranan penting dalam membentuk selera pengguna dan mempunyai implikasi besar terhadap taktik pemasaran. Berbeza dengan segmentasi demografik yang beroperasi dengan pemboleh ubah diskriptif termasuk umur, jantina, saiz keluarga dan kitaran hidup, pendekatan generasi memfokus kepada faktor psikografi kohot, yang mendasari motif dan pencetus jenis tingkah laku tertentu. Memandangkan realiti sosio-politik, budaya dan ekonomi membentuk sistem nilai bersama pada masa remaja mereka, nilai-nilai ini memainkan peranan penting dalam kehidupan mereka. Ciri-ciri utama kohot berterusan sepanjang hayat yang memungkinkan pendekatan generasi dalam pemasaran untuk memfokuskan kepada strategi interaksi jangka panjang dengan pengguna (Parment, 2013).

Tumpuan utama perhatian adalah tertumpu kepada Milenial kerana generasi ini mendapat pengaruh yang signifikan daripada generasi terdahulu, menetapkan trend di semua industri dan pasaran, dan kuasa pembelian tertumpu di tangan mereka. Walau bagaimanapun, pemasar hari ini cenderung beralih kepada generasi $\mathrm{Z}$ yang merupakan generasi muda yang menjadi daya penggerak baru di pasaran. Kumpulan pengguna yang berpengaruh dan unik ini memberikan cabaran kepada pengiklan kerana mereka berbeza dengan generasi $\mathrm{Y}$ walaupun masih bergelar milenial. Apabila milenial dan generasi $\mathrm{Z}$ memasuki alam pekerjaan dan mencapai umur yang ideal semasa bekerja, generasi ini muncul dengan cepat sebagai segmen pasaran yang paling menonjol bukan hanya kerana saiz pasarannya tetapi kerana kuasa pembeliannya.

Oleh kerana kemajuan teknologi dan perubahan dalam landskap pengguna, kebanyakan Milenial menggunakan media sosial secara aktif setiap hari dan mereka dianggap sebagai pengganggu kepada status quo sektor peruncitan tradisional (Topalova, 2021). Disebabkan itu, amat penting bagi pengiklan untuk memahami sikap pengguna Milenial melalui perspektif budaya terhadap pengiklanan media sosial. Ini kerana Milenial bersifat heterogen atau berlainan sehingga sikap dan persepsi mereka secara relatifnya pelbagai maka penerimaan 'suka' dan sikap mereka sentiasa berubah. Sebelum ini, banyak kajian telah menganalisis tentang sikap pengguna terhadap pengiklanan dalam medium yang berasingan dan format yang berbeza, termasuk iklan dalam format yang berbeza dalam satu medium. Walau bagaimanapun, kebanyakan kajian dan penemuan perlu disemak semula dengan era semasa kerana kebanyakan kajian ini dilakukan semasa era internet sedang berkembang tetapi pada masa kini internet merupakan aktiviti biasa untuk semua, maka sikap pengguna seharusnya berbeza daripada yang sebelumnya. Kejayaan sesebuah kempen pengiklanan sangat bergantung kepada sikap dan persepsi pengguna. Sikap kegemaran pengguna terutamanya pengguna Milenial merupakan jalan kepada kejayaan sesebuah pengiklanan. Pandangan mereka sangat penting kerana golongan Milenial merupakan segmen yang berkembang dalam persekitaran digital ini dan merupakan pasaran generasi terbesar di dunia dengan kuasa pembelian yang besar (Laurie, Mortimer \& Beard, 2019; Fry, 2016).

\section{Sosial Media dan Pengiklanan}

Dengan hampir 3.5 bilion pengguna media sosial di seluruh dunia, atau kira-kira 45 peratus daripada populasi dunia, media sosial telah membuktikan kemampuannya untuk menjangkau individu di hampir semua segmen pemasaran yang wujud (Kemp, 2019; Hanna et al., 2011). Secara semula jadinya pertumbuhan media sosial telah menarik perhatian pengamal pengiklanan yang berusaha untuk mempromosi dan meningkatkan jenama mereka melalui kekuatan media sosial dengan menyasarkan kandungan jenama tertentu kepada pengguna sasaran yang tepat. Sehingga Januari 2020, seramai 4.54 bilion penduduk seluruh dunia menggunakan internet, dengan lebih kurang 3.8 bilion orang yang terlibat di media sosial secara aktif, mencapai tahap penembusan sekitar 49 peratus (Digital, 2020). Ia melaporkan bahawa lebih daripada 90 peratus jenama menggunakan lebih dari satu rangkaian media sosial untuk pengiklanan, dan syarikat proaktif dalam menggunakan strategi dan taktik media sosial 
untuk meningkatkan penggunaan jenama mereka (Lee dan Hong, 2016). Lebih penting lagi, peranan media sosial dalam kehidupan pengguna telah menyebabkan pemasar bergantung secara meluas pada platform ini untuk memasarkan keluaran mereka dan selama hampir dua dekad, rangkaian media sosial seperti Facebook, Twitter, Instagram semakin banyak digunakan oleh pemasar untuk mengiklankan jenama mereka (Arora et al., 2019; Lee \& Hong, 2016).

Iklan media sosial telah menjadi titik pusat dalam bidang pemasaran dan pengiklanan beberapa tahun kebelakangan ini. Media sosial merupakan alat penting untuk menghubungkan pengguna tanpa mengira batasan geografi. Kelebihan internet adalah ia membolehkan pengiklan mencapai populasi pengguna secara meluas dan membolehkan pengguna membuat tinjauan, memilih, dan membeli produk dan perkhidmatan daripada pengiklan di seluruh dunia. Media sosial khususnya laman rangkaian sosial menyediakan ruang siber untuk jenama berkomunikasi melalui internet dan mempunyai pengaruh yang kuat untuk memaksa pengiklan menyesuaikan strategi sejajar dengan keperluan media sosial. Pemasar telah melalui proses perkembangan penting apabila internet mengubah peraturan sedia ada dan kebanyakan organisasi melihat peluang untuk mengiklankan di media sosial. Variasi ini digabungkan dalam perancangan media setiap pemasar bagi mencapai berjuta pengguna yang menggunakan media sosial setiap hari.

\section{Sikap Terhadap Pengiklanan Digital dan Tindak Balas Pengguna}

Pengiklanan digital merupakan satu bentuk komunikasi terkini dan terhebat terutama sekali di media sosial. Menurut Lee dan Hong (2016), platform pengiklanan media sosial seperti Facebook, Twitter, dan paling terkini, Tiktok sangat menarik perhatian kerana pengguna dapat berinteraksi dengan pengguna lain dengan menyukai, mengulas, atau berkongsi kiriman. Perkembangan ini memerlukan pengiklan memahami bagaimana dan mengapa pengguna menggunakan media sosial dan selanjutnya bagaimana mengintegrasikan platform ini ke dalam strategi mereka (Cader \& Al Tenaiji, 2013; Whiting \& Williams, 2013). Lee dan Hong (2016) melaporkan bahawa lebih daripada 90 peratus jenama menggunakan lebih daripada satu rangkaian media sosial untuk pengiklanan dan syarikat proaktif dalam menggunakan strategi dan taktik media sosial untuk meningkatkan pembelian dan penggunaan jenama mereka dan ini jelas menunjukkan bahawa pengiklan telah menggunakan populariti media sosial untuk mencapai pembeli, terutama dalam kalangan Milenial yang cenderung bergantung kepada internet. Pengiklan cenderung menggunakan platform media sosial seperti Facebook, YouTube dan Twitter untuk meningkatkan kesedaran jenama, mengumpul maklum balas daripada pengguna, membuat promosi, dan memberikan pautan ke laman web perniagaan (Sreejesh et al., 2020).

Kajian terdahulu menunjukkan bahawa sikap pengguna terhadap iklan mempengaruhi tindak balas mereka terhadap pengiklanan, terutama sekali niat pembelian mereka (Mitchell \& Olson, 1981). El Hedhli, Zourrig dan Becheur (2021) serta Li et al. (2002) berpendapat bahawa tingkah laku tindak balas pengguna seperti mengelak daripada melihat iklan dalam talian, disebabkan sikap negatif mereka terhadap pengiklanan. Sikap negatif ini mungkin disebabkan oleh sifat semula jadi pengiklanan dalam talian yang mengganggu. Begitu juga dengan Tung-Ju Wu et al. (2020) dan Zeng et al. (2009) mendapati bahawa apabila iklan dalam talian menjadi relevan kepada penerima, sikap yang positif terhadap iklan akan wujud dan ia akan bertindak balas dengan baik. Bigne, Simonetti, Ruiz dan Kakaria (2021) menunjukkan hubungan antara sikap pengguna terhadap pengiklanan dalam talian dan pujukan pengguna dan turut mengkaji sikap pengguna muda terhadap pengiklanan media sosial dan tingkah laku tindak balas mereka dan mengakui bahawa kesedaran tentang sesuatu jenama memberi impak kepada sikap pengguna terhadap pengiklanan media sosial, yang mana akhirnya akan memberi kesan kepada tingkah laku tindak balas mereka. Ini jelas menunjukkan bahawa terdapat perkaitan antara sikap pengguna terhadap pengiklanan media sosial dan tindak balas mereka.

Penglibatan pengguna dengan mesej iklan dikenal pasti sebagai salah satu atribut peribadi yang sangat penting dalam mempengaruhi pemprosesan mesej pengiklanan (Grimers, 2008; Keller, 2021). Pengiklan menggunakan pendekatan rasional atau emosi atau keduanya untuk menyatakan atau menterjemah idea kreatif mereka. Pendekatan rasional adalah informatif dan lebih berkesan daripada pendekatan emosi bagi produk baharu di pasaran. Lazimnya, iklan yang menggunakan pendekatan rasional adalah dalam bentuk seperti demonstrasi, testimonial, penyelesaian masalah, kehidupan harian, pengiklanan 
berbentuk drama dan perbandingan manakala iklan menggunakan pendekatan emosi lazimnya terdiri daripada elemen bukan lisan seperti imej dan rangsangan emosi (Pelsmacker et al., 2018). Pendekatan emosi tidak semestinya membangkitkan emosi seseorang. Jenaka, erotikisma, kehangatan, ketakutan, taktik kejutan, dan muzik adalah alat yang lazimnya digunakan dalam pengiklanan yang menggunakan pendekatan emosi (Pelsmacker et al., 2018). Iklan seharusnya menarik dan dapat menyampaikan maklumat yang relevan kepada pengguna. Mehta (2000) berpendapat bahawa individu yang mempunyai sikap yang lebih baik terhadap iklan adalah lebih cenderung untuk yakin dengan iklan. Rangsangan pengiklanan menghasilkan sejumlah proses pengantaraan seperti menghasilkan perhatian, membawa maklumat, membangkitkan penerimaan terhadap mesej, kredibiliti, reaksi afektif positif terhadap iklan dan jenama, pengaktifan, dan niat membeli.

\section{Perbezaan Budaya dalam Sikap}

Manusia yang hidup dalam budaya yang berbeza kebiasaannya berbeza dari segi kepercayaan, pengalaman terdahulu, sikap, nilai, dan lain-lain. Nilai yang berbeza mungkin membawa kepada perbezaan keperluan dan tingkah laku penggunaan. Budaya telah terbukti dapat mempengaruhi tingkah laku dan penggunaan pengguna (Shavitt \& Barnes, 2020). Sebagai contoh, dapat dilihat bahawa pengguna daripada latar belakang budaya yang berbeza mentafsir komunikasi secara berlainan. Penyelidikan juga telah mengemukakan fakta yang menyatakan bahawa pengguna lebih menggemari komunikasi atau produk yang sesuai dengan budaya mereka (Zakaria, Wan-Ismail \& Abdul-Talib, 2020; Jianlin, 2008). Oleh sebab itu, penyelidik terus berusaha untuk mengetahui bagaimana faktor budaya mempengaruhi tingkah laku pengguna dan aktiviti pemasaran tertentu seperti pemasaran media sosial (Khan, Dongping \& Wahab, 2016).

Izogo dan Mpinganjira (2020) serta Tajeddini dan Trueman (2012) menyatakan bahawa budaya mempunyai kesan positif ke atas orientasi pengguna. Kedua Keller (2021) dan Guo et al. (2006) memetik bahawa klasifikasi budaya Hofstede mempunyai pengaruh besar ke atas pengambilan dan penerapan inovasi merentas wilayah. Individu yang berada di wilayah berbeza mempunyai nilai budaya yang berbeza yang boleh memberi kesan mendalam ke atas pemprosesan maklumat pengiklanan. Oleh itu, sikap terhadap pengiklanan digital berbeza di seluruh dunia bergantung kepada penerapan inovasi dan teknologi (Guo et al., 2006). Zarantonello et al. (2014) menunjukkan bahawa kepercayaan agama dan amalan budaya mempengaruhi kegemaran kepada elemen yang digunakan dalam iklan.

Djafarova dan Bowes (2021) dan Usman et al. (2010) berpendapat bahawa persepsi ke atas iklan bergantung kepada penerimaan budaya serta trend dan fesyen baharu. Valaei et al. (2016) pula berpendapat bahawa individualisme mempunyai hubungan positif yang kuat dan orientasi jangka panjang mempunyai hubungan positif sisi bawah dari segi sikap terhadap pengiklanan digital dan sikap terhadap jenama dalam talian. Kekuatan jarak dan sikap terhadap pengiklanan digital mempunyai korelasi positif tetapi ada hubungan negatif antara sifat kelakian dan sikap terhadap jenama dalam talian. Di samping itu, penghindaran ketidakpastian tidak menunjukkan kesan positif ke atas sikap terhadap pengiklanan dalam talian dan sikap terhadap jenama dalam talian.

Abbas (2017) menyatakan bahawa dalam penyelidikan yang dijalankan di Pakistan mendapati bahawa televisyen merupakan media pengiklanan yang paling memberi inspirasi. Satu lagi kajian silang budaya yang dijalankan adalah di Warwick, Beijing, dan Hong Kong. Guo et al. (2006) mendedahkan bahawa secara umumnya manusia mempunyai sikap negatif terhadap pengiklanan dalam talian berbanding media lain. Kumpulan penyelidik ini mendapati bahawa lebih banyak sikap negatif di Warwick (UK). Responden dari Beijing mempunyai sikap yang lebih positif daripada mereka di Hong Kong. Di antara tiga bandar tersebut, terdapat tiga sikap positif yang signifikan terhadap pengiklanan dalam talian dengan mengambil kira ekonomi, peraturan dan kepercayaan peribadi tetapi faktor sosial dan etika dilihat tidak signifikan.

Malaysia pula adalah sebagai sebuah negara yang terdiri daripada masyarakat berbilang budaya dan agama seperti budaya Melayu, Cina, India, dan budaya Eurasia bersama dengan budaya lain. Pribumi Melayu merupakan kumpulan etknik utama di Malaysia dan membentuk norma budaya masyarakat 
(Abu Bakar \& McCann, 2018). Dari segi budaya, Malaysia berbeza dengan negara lain pada beberapa orentasi budaya seperti gender egalitarianism, perikemanusiaan, dan masa depan (Raza \& Abu Bakar, 2019). Malaysia juga berbeza di mana perbezaan agama juga membentuk kepelbagaian budaya masyarakat. Dalam konteks pengiklanan, secara budayanya, pengguna Malaysia menunjukkan ciri sederhana (Kim, Jeong, \& Hwang, 2016).

\section{Dimensi Budaya Nasional Hofstede}

Salah satu model yang paling banyak digunakan untuk memeriksa budaya adalah dimensi budaya Hofstede. Biasanya, ia digunakan untuk mengenal pasti ciri budaya sesuatu pasaran negara (Song, Moon, Chen \& Houston, 2018). Model ini dapat digunakan untuk menjelaskan bagaimana budaya mempengaruhi pengiklanan (Chang et al., 2009) dan pengiklan dapat memanfaatkan model ini kerana dapat membantu mereka memahami bagaimana pendekatan pengiklanan berbeza di antara budaya (Albers-Miller \& Gelb, 1996). Kerangka kerja Hofstede sering digunakan untuk tujuan ini tetapi kerana kurangnya kerangka kerja yang lain yang serasi, kebanyakan penyelidikan yang berfokus kepada budaya dan pengiklanan mungkin dibatasi. Oleh itu, ia telah menerima beberapa kritikan yang mendakwa ia harus diperbaharui agar lebih sesuai dengan nilai-nilai moden (Paek, Nelson \& Vilela, 2011). Namun, melihatkan ramai penyelidik telah menemukan sokongan untuk kerangka tersebut dalam konteks yang lebih moden, seperti pengiklanan elektronik (Saleem et al., 2015), ia masih dilihat berharga untuk mengkaji pengiklanan media sosial.

Untuk menghasilkan komunikasi yang berkesan, tumpuan mesti diberikan kepada pemahaman penerima. Dalam pengiklanan, bahagian tengah seharusnya pengguna (De Mooij \& Hofstede, 2010). Nilai budaya sangat penting kerana ia menentukan keperibadian dan identiti pengguna (De Mooij, 2019). Menurut Hofstede (2001), nilai dalam kes ini dapat dilihat sebagai sesuatu yang secara subjektif menentukan rasionaliti. Selanjutnya, dia menyatakan bahawa perbezaan harus dibuat antara nilai-nilai yang diinginkan dan yang diinginkan: iaitu apa yang diinginkan berbanding dengan apa yang difikirkan. Iklan cenderung untuk menarik nilai yang diinginkan (Hofstede, 2015).

\section{Teori Budaya Hall}

Dalam banyak kes, penyelidikan menggunakan beberapa teori untuk mencapai analisis yang lebih mendalam. Model dimensi budaya Hofstede sering digunakan bersama dengan teori budaya konteks tinggi/rendah. Teori ini diperkenalkan oleh Edward Hall dan mencirikan budaya mengikut bagaimana orang saling berhubung satu sama lain sebagai contoh keharmonian komunikasi dan sosial (Kim, Pan \& Park, 1998). Walaupun berguna, teori Hall mengklasifikasikan budaya mengikut satu dimensi sahaja. Oleh itu, mungkin bermanfaat untuk menggunakannya sebagai pelengkap kerangka kerja Hofstede. Dengan menggunakan teori Hall, aspek komunikasi lisan lebih diambil kira.

Model ini menunjukkan dua konteks ekstrem, tinggi dan rendah dan mengenal pasti budaya mengikut tahap konteks dalam sistem komunikasi manusia (De Mooij, 2019). Dalam budaya komunikasi konteks tinggi, ia bergantung kepada konteks, yang bermaksud bahawa sebilangan besar maklumat berada dalam konteks situasi (De Mooij, 2019). Menurut Hall (1976), seseorang yang memikirkan sesuatu mengharapkan orang lain dalam perbincangan untuk memahami apa yang mengganggunya, tanpa menyatakannya secara langsung. Oleh kerana itu, konfrontasi dapat dihindari dalam budaya ini (Kim et al., 1998). Budaya konteks rendah dicirikan oleh mesej lisan langsung dan eksplisit. Komunikasi yang berkesan ditakrifkan sebagai mesej yang tidak jelas (De Mooij, 2019).

Dalam pengiklanan, perbezaan antara dua jenis budaya ini dilihat daripada pilihan komunikasi. Dalam budaya konteks tinggi, simbol sering digunakan untuk menyampaikan mesej, sedangkan budaya konteks rendah lebih suka berdebat dan retorik. Kerana perbezaan ini, Hofstede mencadangkan hubungan antara konteks tinggi dan dimensi koletivistiknya. Dia menyatakan bahawa maklumat mengalir dengan cara yang serupa dan kurang memerlukan komunikasi eksplisit antara anggota kumpulan dalam budaya kolektivistik daripada individualistik (De Mooij, 2019). 


\section{Penentuan Sikap Ke atas Iklan Dalam Talian}

Pendekatan iklan adalah pengurusan dan pengaturan iklan untuk menarik pengguna secara kreatif. Manusia akan mengingati dan menyukai iklan yang mempunyai ciri-ciri kreatif. Jamiati et al. (2020) dan Ang et al. (2007) memerhatikan bahawa kebaharuan, makna, dan keterhubungan mewujudkan sikap yang baik terhadap iklan. Pemprosesan mendalam kandungan iklan mempromosikan pengiktirafan dan penarikan balik jenama yang lebih tinggi dan juga elemen mesej. Pendekatan pengiklanan berulang mempengaruhi pengguna untuk mengikuti produk atau perkhidmatan, membentuk sikap mereka dan memanipulasi idea atau kecenderungan. Pendekatan pengiklanan mempunyai hubungan positif antara niat tingkah laku dan sikap. Syed et al. (2018) serta Simola et al. (2013) mengesahkan secara empirikal bahawa dalam hal pengiklanan digital, keberkesanan sesebuah iklan sangat bergantung kepada kandungan dan reka bentuknya. Kerumitan visual reka bentuk iklan menarik perhatian penonton pada tahap tertentu.

Sikap lazimnya ditakrifkan sebagai perasaan baik atau tidak baik seseorang dan penilaian tentang melakukan tingkah laku tertentu (Fishbein \& Ajzen, 1975). Dalam konteks pengiklanan, Lutz (1985) mengemukakan sikap terhadap iklan sebagai kecenderungan untuk bertindak balas terhadap insentif pengiklanan tertentu semasa terdedah kepadanya dalam keadaan tertentu. Manakala Luna-Nevarez dan Torres (2015) pula mendefinisikan sikap terhadap pengiklanan media sosial sebagai kecenderungan untuk memberi respons baik atau sebaliknya terhadap kandungan iklan di media sosial. Jika tidak, telah dibahaskan bahawa sikap merupakan faktor penentu dalam perubahan tingkah laku (Lee \& Chow, 2020; Kimelfeld \& Watt, 2001). Dianggap sebagai asas sikap dalam banyak aspek sosial kehidupan, nilai juga adalah asas terkehadapan bagi sikap terhadap pengiklanan (Beatty et al., 1985). Sesungguhnya, berdasarkan kepada model nilai pengiklanan, sikap terhadap pengiklanan tradisional dan digital sangat mempengaruhi nilai yang dirasakan terhadap sesuatu iklan (Dessy et al., 2020; Ducoffe, 1996; Brackett \& Carr, 2001). Selain itu, Tong, Luo dan Xu (2019) serta Haghirian dan Madlberger (2005) berpendapat bahawa nilai pengiklanan mudah alih telah menunjukkan kesan yang signifikan ke atas sikap terhadap pengiklanan mudah alih.

Telah dikatakan bahawa sikap pengguna terhadap pengiklanan mempengaruhi tindak balas mereka terhadap iklan tersebut (Mitchell \& Olson, 1981). Sebagai contoh, sikap negatif terhadap pengiklanan dalam talian dianggap mengganggu dan menjengkelkan menimbulkan tindak balas tingkah laku pengguna yang tidak baik seperti mengelak daripada terdedah kepada iklan dalam talian (Djafarova \& Bowes, 2021). Sebaliknya, lebih suka seseorang pengguna terhadap iklan dalam talian kerana sifat interaktiviti atau personalitinya, semakin positif sikap mereka terhadapnya dan seterusnya bertindak balas dengan baik (Lin et al., 2021; Zeng et al., 2009; Logan et al., 2012). Beberapa kajian juga menunjukkan bahawa sikap pengguna terhadap pengiklanan media sosial mempengaruhi tindak balas mereka terhadapnya (Sun \& Wang, 2010; Chu et al., 2013; Boateng \& Okoe, 2015). Sebagai contoh, Lin, Crowe, Pierre dan Lee (2021) menyoroti bahawa tindak balas tingkah laku pengguna yang baik, seperti mengklik iklan media sosial untuk mendapatkan maklumat lanjut atau membuat pembelian produk yang diiklankan di media sosial adalah hasil dari sikap pengguna yang baik terhadap iklan (Dreze \& Zufryden, 1997; Mir, 2012).

\section{Kesimpulan}

Media sosial menunjukkan perkembangan pesat dalam beberapa tahun kebelakangan ini. Iklan yang terpapar di platform ini menarik perhatian pengguna media sosial terutama sekali pengguna Milenial dan kajian menunjukkan sikap pengguna adalah penting dalam menentukan keberkesanan sesuatu pengiklanan di media sosial dan sikap pengguna terhadap iklan mempengaruhi tindak balas mereka terhadap pengiklanan, terutama sekali niat pembelian mereka.

Sikap merupakan konsep yang sering digunakan supaya individu memahami dan bertindak balas terhadap situasi dan keadaan yang berbeza. Sikap juga membantu untuk mengukur kecenderungan pengguna untuk bertindak balas terhadap mesej tertentu secara positif atau negatif. 
Sikap terhadap pengiklanan diterima umum sebagai penunjuk utama keberkesanan pengiklanan kerana kaitan ramalannya dengan tingkah laku. Sikap sedemikian didakwa dibina terutamanya berdasarkan kepercayaan terhadap pengiklanan. Sikap terhadap konstruk pengiklanan adalah kecenderungan naluri untuk bertindak balas dengan baik atau tidak terhadap pengiklanan secara umum. Berdasarkan beberapa kajian yang telah dijalankan, faedah utama persepsi pengiklanan secara amnya adalah konstruk ini merupakan sebahagian daripada teori rangkaian perhubungan berkenaan kesan pengiklanan terhadap individu.

Budaya pula memainkan peranan yang penting dalam menjelaskan mengapa terdapat perbezaan dalam proses membuat keputusan oleh pengguna. Budaya dianggap sebagai konsep yang tidak dapat diukur (De Mooij, 2015). Pemain industri pengiklanan perlu menghargai perbezaan budaya dan bangsa individu. Dalam memahami keutamaan pengiklanan pengguna Milenial, pengiklan dan agensi pengiklanan mungkin perlu melokalisasikan mesej pengiklanan mereka kepada pasaran Milenial dan akan menimbulkan reaksi yang berbeza daripada pengguna Milenial ini. Perbezaan dalam sikap terhadap pengiklanan dalam kalangan Milenial adalah kerana faktor-faktor seperti nilai, amalan, dan peraturan.

Pengguna Milenial bersifat heterogen atau berlainan sehingga sikap dan persepsi mereka secara relatifnya pelbagai maka penerimaan 'suka' dan sikap mereka sentiasa berubah. Berbanding dengan generasi kohot yang lain, golongan Milenial sukar untuk digeneralisasikan kerana persepsi dan sikap mereka yang berlainan antara satu individu dengan individu yang lain terutama sekali Generasi Z. Disebabkan itu, Milenial tidak boleh dikonseptualisasikan sebagai satu pasaran khusus (eMarketer, 2017). Penemuan telah mendedahkan bahawa kumpulan pengguna ini masih sering disalah anggap. Walaupun Milenial merupakan sub-segmen pengguna pelbagai yang memerlukan pelan komunikasi pemasaran yang unik, mereka tetap dianggap sebagai satu kumpulan pengguna sahaja (Bucic et al., 2012). Disebabkan salah faham yang berlaku, ia boleh menyebabkan ketidakberkesanan program komunikasi dan pemasaran.

Pengguna Milenial di Malaysia hidup dalam budaya yang berbilang kaum dan berbeza dari segi kepercayaan, pengalaman, sikap, nilai dan ini menyebabkan wujudnya perbezaan keperluan dan tingkah laku dalam kalangan pengguna. Budaya telah terbukti dapat mempengaruhi tingkah laku kerana latar belakang pengguna yang berbeza mentafsir komunikasi secara berlainan selain daripada pengguna lebih menggemari komunikasi atau produk yang sesuai dengan budaya mereka. Kedudukan geografi seseorang individu juga memberi kesan kepada pemprosesan maklumat pengiklanan kerana ianya bergantung kepada penerapan individu terhadap inovasi dan teknologi. Amalan budaya juga turut mempengaruhi kegemaran kepada elemen yang digunakan dalam iklan dan ini kerana budaya mempunyai kesan positif ke atas sikap dan orientasi pembelian pengguna.

Penggunaan teori-teori pengiklanan dan tingkah-laku pengguna berbilang bangsa dan budaya dilihat sebagai isu penting ekonomi global. Walau bagaimanapun, terdapat kajian empirikal yang terhad yang membandingkan dimensi sikap ke atas pengiklanan secara umum dalam kalangan pengguna daripada negara dan budaya yang berbeza. Perbezaan sikap terhadap pengiklanan adalah menarik bagi kajian sebegini. Penemuan seperti ini memberi amaran tentang bahaya etnosentrisme. Pengiklan juga dilihat cenderung untuk menjalankan penyelidikan pasaran yang teliti untuk mendapatkan pemahaman yang lebih baik dan kepekaan terhadap persekitaran budaya untuk mengelak kesalahan pengiklanan antarabangsa sebelum menghasilkan piawaian pendekatan pengiklanan. Perbandingan kumpulan pengguna merentas budaya menyumbang kepada literatur mengenai sikap dan kepercayaan terhadap pengiklanan secara umum. Selain itu, hasil kajian sebegini dapat memberi panduan empirikal perbandingan milenial merentas budaya dan ekonomi/pasaran maju dan berkembang untuk digunakan oleh kedua ahli akademik dan pengamal pengiklanan antarabangsa.

Melihat kepada perkembangan trend global dan pergerakan ke arah ekonomi yang lebih berorientasikan pasaran, menilai aplikasi konstruk pengiklanan dan tingkah-laku pengguna, ukuran dan teori untuk bangsa dan budaya lain menjadi satu isu penting yang perlu ditangani. 


\section{Rujukan}

Abbas, A. (2017) Consumer attitude towards Web sites and Internet advertising. Business, 1-11. 10.13140/RG.2.2.35849.65123

Abu Bakar, H., \& McCann, R. (2018). Workgroup diversity: Surface -evel actual similarity abd deeplevel perceived similarity in leader-member relationship communication. Corporate Communication Journal.

Albers-Miller, N. D., \& Gelb, B. D. (1996). Business Advertising Appeals as a Mirror of Cultural Dimensions: A Study of Eleven Countries, Journal of Advertising, 25(4), 57-70.

Al Kurdi, B., \& Alshurideh, M. (2021). Facebook Advertising as a Marketing Tool: Examining the Influence on Female Cosmetic Purchasing Behaviour. International Journal of Online Marketing (IJOM).

Ang, S. H.-Lee, Y. H.-Leong, S.M. (2007) The ad creativity cube: conceptualization and initial validation. Journal of the Academy of Marketing Science, 35(2), 220232.https://doi.org/10.1007/s11747-007-0042-4

Arora, A., Bansal, S., Kandpal, C., Aswani, R., \& Dwivedi, Y. (2019). Measuring social media influencer index-insights from facebook, Twitter and Instagram. Journal of Retailing and Consumer Services, 49, 86-101.

Bamoriya, H.-Singh, R. (2011) Information seeking and attitude towards advertising- a crosssectional empirical study. Journal of Applied Management \& Computer Science, 3(1), 1-21.

Beatty, S.E., Kahle, L.R., Homer, P. \& Shekhar, M. (1985). Alternative measurement approaches to consumer values: The list of values and the rokeach value survey. Psychology and Marketing, 2(3), 181-200.

Bigne, E., Simonetti, A., Ruiz, C., \& Kakaria, S. (2021). How online advertising competes with usergenerated content in TripAdvisor. A neuroscientific approach. Journal of Business Research.

Boateng, H. \& Okoe, A.F. (2015). Consumers' attitude towards social media advertising and their behavioural response. Journal of Research in Interactive Marketing, 9(4), 299-312

Brackett, L. K. \& Carr, B. N. (2001). Cyberspace advertising vs. Other media: Consumer vs. mature student attitudes. Journal of Advertising Research, 41(5), 23-33.

Cader, Y., \& Al Tenaiji, A. A. (2013). Social media marketing. International Journal of Social Entrepreneurship and Innovation, 2(6), 546-560. doi:10.1504/IJSEI.2013.059955

Chang, T. K., Huh, J., McKinney, K., Sar, S., Wei, W., \& Schneeweis, A. (2009). Culture and its influence on advertising: Misguided framework, inadequate comparative design and dubious knowledge claim. International Communication Gazette, 71(8), 671-692.

Chu, S.C., Kamal, S. and Kim, Y. (2013). Understanding consumers' responses toward social media advertising and purchase intention toward luxury products. Journal of Global Fashion Marketing, 4(3), 158-174.

De Mooij, M., \& Hofstede, G. (2010). The Hofstede model: Applications to global branding and advertising strategy and research. International Journal of advertising, 29(1), 85-110.

De Mooij, M. (2015). Cross-cultural research in international marketing: clearing up some of the confusion. International Marketing Review, 32(6).

De Mooij, M. (2019). Global marketing \& advertising: understanding cultural paradoxes (5th ed.). London: SAGE Publications.

Dessy Kurnia Sari, Suziana Suziana, \& Donard Games. (2020). An evaluation of social media advertising for Muslim millennial parents. Journal of Islamic Marketing.

Digital (2020). Digital 2020 global overview report. https://wearesocial.com/blog/2020/01/digital2020-3-8-billion-people-use-social-media/.

Djafarova, E., \& Bowes, T. (2021). 'Instagram made Me buy it': Generation Z impulse purchases in fashion industry. Journal of Retailing and Consumer Services.

Dreze, X. \& Zufryden, F. (1997). Is Internet Advertising Ready For Prime Time. Journal of Advertising Research, 38(3), 7-18.

Ducoffe, R. H. (1995). How Consumers assess the value of advertising. Journal of Current Issues and Research in Advertising, 17, 1-18.

El Hedhli, K., Zourrig, H., \& Becheur , I. (2021). Celebrity endorsements: Investigating the interactive effects of internalization, identification and product type on consumers' attitudes and intentions. Journal of Retailing and Consumer Services. 
Fishbein, M. (1967). Readings in Attitude. Theory and Measurement. Wiley, New York.

Fishbein, M.-Ajzen, I. (1975). Belief, attitude, intention, and behavior: An introduction to theory and research. Reading. Addison-Wesley, California.

Fry, R. (2018). Millennials are the largest generation in the U.S. labor force. Washington: Pew Research Center.

Guo, G.-Cheung, F. S-L.-Leung, W-F.-Chow, C. W-C. (2006). Attitudes towards internet advertising: a cross-cultural study. International Journal of Internet Marketing and Advertising, 3, 2, pp.158-176. 10.1504/IJIMA.2006.010297

Haghirian, P., Madlberger, M., \& Tanuskova, A. (2005). Increasing advertising value of mobile marketing - an empirical study of antecedents. Paper presented at the

Hall, E.T. (1976). Beyond culture. New York: Doubleday.

Hanna, R., Rohm, A. \& Crittenden, V.L. (2011). We're all connected: the power of the social media ecosystem. Business Horizons, 54(3), 265-273.

Hofstede, G. (2001). Culture's consequences: Comparing values, behaviors, institutions and organizations across nations. Thousand Oaks, CA: SAGE Publications.

Hofstede, G. (2015). National differences in communication styles. In D. Brzozowska \& W. Chlopicki (Ed.), Culture's Software: Communication Styles (p.1-14). Newcastle upon Tyne: Cambridge Scholars Publishing

Ibrahim, B. (2021). Social Media Marketing Activities and Brand Loyalty: A Meta-Analysis Examination. Journal of Promotion Management .

Izogo, E., \& Mpinganjira, M. (2020). Behavioral consequences of customer inspiration: the role of social media inspirational content and cultural orientation. Journal of Research in Interactive Marketing.

Jamiati KN, Naila Waliya Hamima, \& Velda Ardia. (2020). Analysis Of Tokopedia's Advertising Creativity "Waktu Indonesia Belanja". The Indonesian Journal of Communication Studies.

Jianlin, F. L. L. H. W. (2008). Cultural Discount and Cross-Cultural Predictability: Examing the Box Office Performance of American Movies in Hong Kong. Studies in Culture \& Art, (1), 31.

Keller, V. (2021). Consumer Attitude Toward E-Advertising from an Intercultural Perspective. TérGazdaság-Ember Journal.

Kemp, S. (2019). Digital trends 2019: every single stat you need to know about the internet, available at: $\quad$ https://thenextweb.com/contributors/2019/01/30/digital-trends-2019-every-single-statyouneed-to-know-about-the-internet/

Khan, I., Dongping, H., \& Wahab, A. (2016). Does culture matter in effectiveness of social media marketing strategy? An investigation of brand fan pages. Aslib Journal of Information Management, 68(6), 694-715.

Kim, D., Pan, Y., \& Park, H. S. (1998). Hig_h_-v_e_rsus low-C_o_n_t_ext culture: A comparison of Chinese, Korean, and American cultures. Psychology \& Marketing, 15(6), 507-521.

Kim, S., Jeong, S.-H., \& Hwang, Y. (2016). Why are there cross-national differences in response to comparative advertising?: some mediators. Journal of Marketing Communications.

Kimelfeld, Y. M., \& Watt, J. H. (2001). The pragmatic value of on-line transactional advertising: A predictor of purchase intention. Journal of Marketing Communications, 7(3), 137-157.

Kraus, M. (2018). Comparing Generation X and Generation Y on their Preferred Emotional Leadership Style. Journal of Applied Leadership and Management, 62-75.

Laurie, S., Mortimer, K., \& Beard, F. (2019). Has Advertising Lost Its Meaning? Views of UK and US Millennials. Journal Of Promotion Management.

Lee J \& Hong I.B. (2016). Predicting positive user responses to social media advertising: Theroles of emotional appeal, informativeness, and creativity. International Journal of Information Management, 36, 360-373.

Lee, S. H., \& Chow, P.-S. (2020). Investigating consumer attitudes and intentions toward online fashion renting retailing. Journal of Retailing and Consumer Services.

Li, H., Edwards, S.M. and Lee, J.H. (2002). Forced exposure and psychological reactance: antecedents and consequences of the perceived intrusiveness of pop-up ads. Journal ofAdvertising, 31(3), 8395.

Lin, C. A., Crowe, J., Pierre, L., \& Lee, Y. (2021). Effects of Parasocial Interaction with an Instafamous Influencer on Brand Attitudes and Purchase Intentions. The Journal of Social Media in Society. 
Logan, K., Bright, L.F. \& Gangadharbatla, H. (2012). Facebook versus television: advertising value perceptions among females. Journal of Research in Interactive Marketing, 6(3), 164-179.

Luna-Nevarez, C., \& Torres, I. M. (2015). Consumer Attitudes Toward Social Network Advertising. Journal of Current Issues and Research in Advertising.

Lutz, R. J. (1985). Affective and cognitive antecedents of attitude toward the ad: A conceptual framework, in Alwitt, L.F. and Mitchell, A.A. (Ed.), Psychological processes and advertising effects: Theory, research and application, Lawrence Erlbaum Associates, Hillsdale, NJ, pp. 4563.

MAGNA. (2020). Magna Global Advertising Forecasts - June 2020. New York: Magna.

MAGNA. (2021). Magna Global Advertising Forecasts - June 2021 JUNE 13, 2021. New York: MAGNA .

Mehta, A. (2000). Advertising Attitudes and Advertising Effectiveness. Jounral of Advertising Research 40(3), 67-72

Mir, I.A. (2012). Consumer attitudinal insights about social media advertising: A South Asian perspective. The Romanian Economic Journal, 15(45), 265-288.

Mitchell, A.A. \& Olson, J.C. (1981). Are product attributes the only mediator of advertising effects on brand attitude?. Journal of Marketing Research, 18(3), 318-332.

Niu, X., Wang, X., \& Liu, Z. (2020). When I feel invaded, I will avoid it: The effect of advertising invasiveness on consumers' avoidance of social media advertising. Journal of Retailing and Consumer Services.

Northey, G., Dolan, R., Etheridge, J., Septianto, F., \& van Esch, P. (2020). LGBTQ Imagery in Advertising How Viewers' Political Ideology Shapes Their Emotional Response to Gender And Sexuality in Advertisements. Journal of Advertising Research.

Paek, H. J., Nelson, M. R., \& Vilela, A. M. (2011). Examination of gender-role portrayals in television advertising across seven countries. Sex roles, 64(3), 192-207.

Parment, A. (2013). Generation Y vs. Baby Boomers: Shopping behavior, buyer involvement and implications for retailing. Journal of Retailing and Consumer Services (20), 189-199.

Pelsmacker, P. D.- Geuens, M.- Bergh, J. V. (2018) Marketing Communications. A European Perspective. Pearson Prentice Hall, Essex.

Rajakrishnan, M., \& Brindha, N. (2021). Consumer Belief And Attitude Towards Social Media Marketing. Aegaeum Journal.

Raza, S., \& Abu Bakar, H. (2019). The effects of advertising appeals on consumers' behavioural intention towards global brands: the mediating role attitude and the moderating role of uncertainty avoidance. Journal of Islamic Marketing.

Saha, T., Kumar, N., Jannat, F., \& Nahar, N. (2021). Influence of Social Media on Brand Positioning and Brand Equity: A Study on Fast Moving Consumer Goods of Bangladesh. European Journal of Business and Management.

Saleem, S., Larimo, J. A., Ummik, K., \& Kuusik, A. (2015). Cultural and paradoxical values in advertising in Eastern Europe: Evidence from Estonia. Baltic Journal of Management, 10(3), 313330 .

Shavitt, S., \& Barnes*, A. J. (2020). Culture and Consumer Journey. Journal of Retailing.

Simola, J., Kivikangas, M., Kuisma, J., \& Krause, C. M. (2013). Attention and memory for newspaper advertisements: Effects of ad-editorial congruency and location. Applied Cognitive Psychology, 27(4), 429-442.

Song, R., Moon, S., Chen, H. A., \& Houston, M. B. (2018). When marketing strategy meets culture: the role of culture in product evaluations. Journal of the Academy of Marketing Science, 46(3), 384-402.

Sreejesh, S., Paul, J., Strong, C., \& Pius, J. (2020). Consumer response towards social media advertising: Effect of media interactivity, its conditions and the underlying mechanism. International Journal of Information Management.

Sun, S. \& Wang, Y. (2010). Examining the role of beliefs and attitudes in online advertising: a comparison between the USA and Romania. International Marketing Review, 27(1), 87-107.

Syed R.-Bakar, A.-Bahtiar, M. (2018) Relationships between the Advertising Appeal and Behavioral Intention: The Mediating role of the Attitude towards Advertising Appeal. Journal of Business and Retail Management Research, 12(2), 185-193. 10.24052/ JBRMR/V12IS02/RBTAAABITMROTATAAAMROCN 
Tajeddini, K.-Trueman, M. (2012) Managing Swiss hospitality: how cultural antecedents of innovation and customer-oriented value systems can influence performance in the hotel industry. International Journal of Hospitality Management, 31(4), 1119-1129. https://doi.org/10.1016/j.ijhm.2012.01.009

Tong, S., Luo, X., \& Xu, B. (2019). Personalized mobile marketing strategies. Journal of the Academy of Marketing Science.

Topalova, N. (2021). The impact of marketing through Instagram influencers on consumer behavior in the fashion industry: comparison of Millennials and Generation $Z$ in Russia. Geneva: Geneva Business School.

Tung-Ju Wu, Ting Xu, Lydia Qianqian Li, \& Kuo-Shu Yuan. (2020). Touching with heart, reasoning by truth"! The impact of Brand cues on mini-film advertising effect. International Journal of Advertising.

Usman, M.-Ilyas, S. M.- Hussain, M. F.- Qureshi, T. M. (2010) General Attitude towards Advertising: Cultural Influence in Pakistan. International Journal of Marketing Studies, 2(2), 124-133. 10.5539/ijms.v2n2p124

Valaei, N.-Rezaei, S.-Wan, I. W. K.-Oh, Y. M. (2016) The effect of culture on attitude towards online advertising and online brands: applying Hofstede's cultural factors to internet marketing. International Journal of Internet Marketing and Advertising, 10(4), 270-301. 10.1504/IJIMA.2016.10002253

van Berlo, Z. M., van Reijmersdal, E. A., \& Eisend, M. (2021). The Gamification of Branded Content: A MetaAnalysis of Advergame Effects. Journal of Advertising.

van Ooijen, I., \& Segijn, C. (2020). Differences in consumer knowledge and perceptions of personalized advertising: Comparing online behavioural advertising and synced advertising. Journal of Marketing Communications.

Whiting, A., \& Williams, D. (2013). Why people use social media: A uses and gratifications approach. Qualitative Market Research: An International Journal, 16(4), 362-369. doi:10.1108/QMR-062013-0041

Worldometers. (2020). Malaysia demographics. $\quad$ Retrieved from https://www.worldometers.info/demographics/malaysia-demographics/

Zakaria, N., Wan-Ismail, W.-N., \& Abdul-Talib, A.-N. (2020). Seriously, conspicuous consumption? The impact of culture, materialism and religiosity on Malaysian Generation Y consumers' purchasing of foreign brands. Asia Pacific Journal of Marketing and Logistics.

Zarantonello, L.-Schmitt, B.-Kamel J. K. (2014) How to Advertise and Build Brand Knowledge Globally: Comparing Television Advertising Appeals across Developed and Emerging Economies. Journal of Advertising Research, 54(4), 1-23. 10.2501/JAR-54-4-420-434

Zeng, F., Huang, L. \& Dou, W. (2009). Social factors in user perceptions and responses to advertising in online social networking communities. Journal of Interactive Advertising, 10(1), 1-13. 